\title{
Evaluation of the Pharmacokinetics of the Simultaneous Quantification of Letrozole and Palbociclib in Rat Plasma by a Developed and Validated HPLC-PDA
}

\author{
Mona Al-Shehri ${ }^{1}$, Mohamed Hefnawy ${ }^{1,2}$, Hatem Abuelizz ${ }^{1}$ and Adeeba Alzamil ${ }^{{ }^{*}}$ \\ 'Department of Pharmaceutical Chemistry, College of Pharmacy, King Saud University, P.O. Box 2457, \\ Riyadh 11451, Saudi Arabia \\ 2Department of Analytical Chemistry, Faculty of Pharmacy, Mansoura University, Mansoura 35516, Egypt
}

Received: 01 Apr 2019; accepted: 01 Sep 2019

\begin{abstract}
The US Food and Drug Administration (FDA) has affirmed the use of letrozole (LTZ) combined with palbociclib (PLB) to treat breast malignant tumor growth in postmenopausal women. A straightforward and extremely sensitive reversed-phase high-performance liquid chromatography method with photodiode array detection (RP-HPLC-PDA) was created and validated for the simultaneous determination of LTZ and PLB in rat plasma. The parameters used to give the best separation were a C18 column $(150 \mathrm{~mm} \times 4.6 \mathrm{~mm}, 3.5 \mu \mathrm{m})$ as the stationary phase with an isocratic mobile phase composed of methanol-30 mM ammonium acetate at a ratio of 60:40 (v/v), $\mathrm{pH}=5.5$, a flow rate of $0.8 \mathrm{~mL} / \mathrm{min}$, and detection wavelengths of 240 and $220 \mathrm{~nm}$ for LTZ and PLB, respectively. The developed method was assessed by the FDA rules over a range of $10-600 \mathrm{ng} / \mathrm{mL}$ for LTZ and PLB. The mean of \%recovery of LTZ and PLB extracted from rat plasma by acetonitrile-based deproteinization was $91.06 \pm 2.73$ and $90.30 \pm 1.95 \%$, respectively, and the limits of detection were $5 \mathrm{ng} / \mathrm{mL}$ for LTZ and $7 \mathrm{ng} / \mathrm{mL}$ for PLB in rat plasma. The mean values of $T_{\max }$ and $C_{\max }$ were $6 \pm 0.00 \mathrm{~h}$ and $266.96 \pm 21.23 \mathrm{ng} / \mathrm{mL}$ for LTZ and $4 \pm 0.00 \mathrm{~h}$ and $508.75 \pm 61.56 \mathrm{ng} / \mathrm{mL}$ for PBL, respectively, after intraperitoneal administration of both drugs to rats. The developed HPLC-PDA method was demonstrated to be robust and was effectively applied to study the pharmacokinetics of LTZ and PLB in rat plasma.
\end{abstract}

Keywords: letrozole, palbociclib, HPLC-PDA, simultaneous quantification, pharmacokinetics, breast cancer, rat plasma

\section{Introduction}

The most widely recognized tumor kind for females is breast cancer. The treatment of breast cancer disease relies upon the stage and sort of malignant growth [1]. Palbociclib (PLB) combined with letrozole (LTZ) has been affirmed to treat of estrogen receptor (ER)-positive epidermal growth factor receptor 2 (HER2)-negative breast malignancy in postmenopausal women [2-4]. On March 2017, the US Food and Drug Administration (FDA) approved the use of PLB in combination with LTZ for treatment of ER-positive and HER2negative cancer [5]. Palbociclib (IBRANCE ${ }^{\circledR}$, Pfizer Inc.) was developed to overcome the drawbacks of first-generation cyclin-dependent kinase (CDK) inhibitors [6, 7]. PLB is an oral, potent, and selective CDK4/6 inhibitor, which has shown promising antitumor activity, particularly against the estrogen receptor alpha positive $(\mathrm{ER} \alpha+)$ breast cancer subtype [8]. PLB is absorbed and reach $C_{\max }$ after $4-8 \mathrm{~h}$. It was reported that PLB is liable to hepatic metabolism, with the major metabolic pathways related to oxidation and sulfonation, and the minor pathways related to acylation and glucuronidation [9, 10]. To the best of our knowledge, there have been no studies to date on the metabolites of PLB [11]. Letrozole (Femara ${ }^{\circledR}$ ) is from an aromatase enzyme system, which is a nonsteroidal competitive inhibitor. Its competitive binding to the heme in

*Author for correspondence: E-mail: adeebaalzamil@gmail.com; Tel: $+966504298812$ the cytochrome P450 subunit of the enzyme tends to inhibit the transformation of androgens to estrogens, thus lowering estrogen biosynthesis in all tissues [12]. LTZ is quickly and completely absorbed from the gastrointestinal tract. It metabolized slowly to an inactive carbinol metabolite (CBL, bis(cyanophenyl)methanol) [13]. The major clearance pathway of this metabolite occurs via its glucuronide conjugate, which is excreted renally. The terminal elimination half-life of LTZ is nearly 2 days, and its steady-state plasma concentration is achieved in 2-6 weeks after a daily $2.5-\mathrm{mg}$ dosing. LTZ has a large volume of distribution (nearly $1.9 \mathrm{~L} / \mathrm{kg}$ ) and binds proteins weakly [14]. The chemical structures of LTZ and PLB are shown in Figure 1.

Several analytical techniques have been published for the determination of letrozole alone. First of all, spectrometric methods were applied on LTZ dosage forms [15-17], and the highest sensitivity among them was linear in the range 0.25 to $20 \mu \mathrm{g} / \mathrm{mL}$ [17]. Different high-performance liquid chromatography-UV detection (HPLC-UV) methods are reported to determine LTZ in pharmaceutical dosage forms [18-26]. The best sensitivity among those methods was reported by Mondal et al., [24] ranging from 1 to $50 \mu \mathrm{g} / \mathrm{mL}$, and the limit of detection (LOD) and limit of quantification (LOQ) were $0.207 \mu \mathrm{g} / \mathrm{mL}$ and $0.627 \mu \mathrm{g} / \mathrm{mL}$, respectively. Acharjya et al. [27] developed a method to study the pharmacokinetic of letrozole in Wistar rat serum. The analytical method was a selective, with a linearity range of $0.15-100 \mu \mathrm{g} / \mathrm{mL}$. LOQ was evaluated to be $0.15 \mu \mathrm{g} / \mathrm{mL}$. In addition, there are different techniques developed, namely, capillary gas chromatography

This is an open-access article distributed under the terms of the Creative Commons Attribution-NonCommercial 4.0 International License (https://creativecommons.org/licenses/by-nc/4.0/), which permits unrestricted use, distribution, and reproduction in any medium for non-commercial purposes, provided the original author and source are credited, a link to the CC License is provided, and changes - if any - are indicated. 

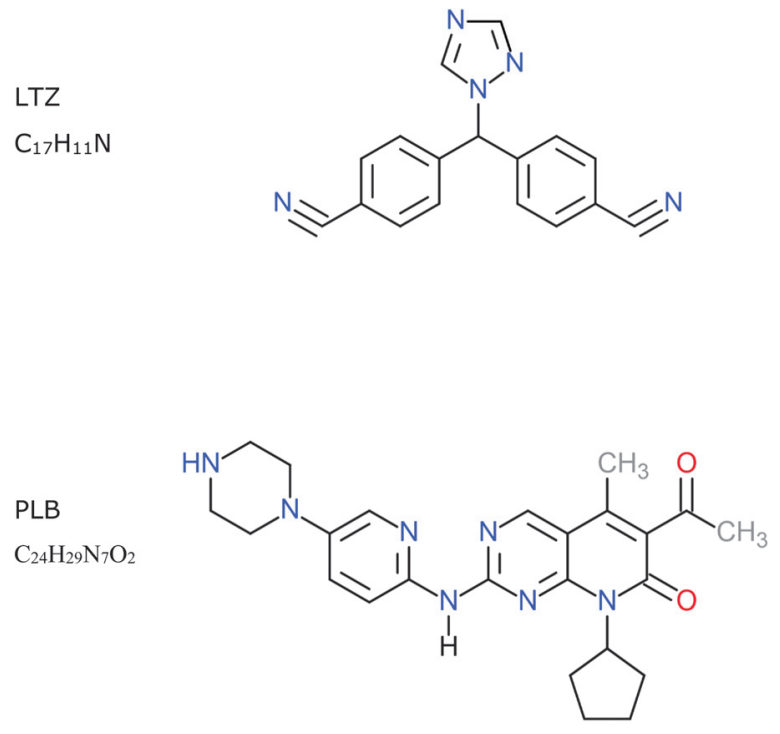

Figure 1. Chemical structures of the studied drugs letrozole (LTZ) and palbociclib (PLB)

with flame ionization detection (FID) for the analysis of LTZ in dosage forms (LOD: $30.6 \mu \mathrm{g} / \mathrm{mL}$ ) [28] and micellar electrokinetic chromatography (MEKC) [29-32] methods, which are the best in the analysis of LTZ in biological (human serum, saliva, and urine) with a linearity range of $125-1500 \mathrm{ng} / \mathrm{mL}$ and detection limits of 37 to $120 \mathrm{ng} / \mathrm{mL}$ in biological samples and of $6 \mathrm{ng} / \mathrm{mL}$ in water samples [32]. HPLC with fluorescence detection [33-36] or mass spectrometry [37-45] was sensitive compared to the above mention techniques, and was therefore used in the pharmacokinetic study of letrozole.

For determination of PLB, there are few validated reversedphase HPLC with photodiode array detection (RP-HPLCPDA) methods for determination of PLB in pharmaceutical formulations with a difference in the sensitivity or level of LOD and LOQ [46-50]. PLB was determined in human plasma by a HPLC-UV method, and the plasma samples were prepared by solid-phase extraction, utilizing an Oasis hydrophilic-lipophilic parity extraction cartridge $(1 \mathrm{~mL} ; 30 \mathrm{mg})$. The lower limit of detection was $50 \mathrm{ng} / \mathrm{mL}$ [51]. PLB does not have natural fluorescence like LTZ; therefore, it is not reported in any publications on the use of fluorescence detection. There were liquid chromatography-tandem mass spectroscopy (LC-MS/MS) methods mention in a clinical study without validation for determination of PLB in human plasma with a LOD of $1.0 \mathrm{ng} / \mathrm{mL}$ [52], in mouse plasma using protein precipitation as an extraction method with a linearity of 1.0 $1000 \mathrm{ng} / \mathrm{mL}$ [53], and in rat, dog, and rabbit plasma [54]. There is one method reported for determination of LTZ with PLB in the dosage form. A RP-HPLC method have been developed and validated to measure PLB and LTZ at a single wavelength $(254 \mathrm{~nm})$. The LODs for PLB and LTZ were found to be 0.098 and $0.0821 \mu \mathrm{g} / \mathrm{mL}$, while the LOQs were 0.381 and $0.315 \mu \mathrm{g} / \mathrm{mL}$, respectively [55].

An extensive review of the literature did not show any methods that simultaneously analyze LTZ and PLB in plasma by RP-HPLC. The approval of LTZ combination with PLB for the treatment of breast cancer was the basis for developing a method to determine these two drugs simultaneously. Therefore, the aim of our study is to develop a RP-HPLC-PDA method with the selectivity and sensitivity needed to determine low concentrations of LTZ and PLB combination in rat plasma. After development and validation, the method will be applied to investigate the pharmacokinetics of LTZ and PLB in rats treated with these drugs.

\section{Experimental}

Reagents and Materials. PLB and LTZ with analytical purity $>99 \%$ used as reference standards were acquired from Toronto Research Chemicals (Toronto, Ontario, Canada). Internal standard (IS) was paracetamol (reference standard; analytical purity $>99 \%$ ), and analytical level ammonium acetate and acetic acid were taken from WINLAB laboratory chemicals reagents fine chemicals (UK). Methanol and acetonitrile (HPLC-grade solvents, Panreac, Barcelona, Spain) were used in the study. Deionized water obtained from the Milli-Q ${ }^{\circledR} \quad$ Advantage Water Purification System and a Millipore membrane filter $(0.2 \mathrm{~mm}$, Nihon, Millipore, Molsheim, France) were used throughout the experiments. Laboratory (healthy adult male Swiss albino) rats were obtained from the King Saud University (Pharmacy College, Experimental Animal Care Centre).

Apparatus and Chromatographic Conditions. A novel validated method was carried out on an HPLC instrument (WATERS, USA) equipped with a binary pump (Waters 1525), a photodiode array detector (Waters 2998), and an autosampler (Waters 2707). The data processing system includes a Dell personal computer and a Breeze 2 program. The stationary phase used was a C18 $(4.6 \mathrm{~mm} \times 150 \mathrm{~mm}$, $3.5 \mu \mathrm{m}$ ) column purchased from WATERS (USA). The mobile phase was consisted of methanol-30 mM ammonium acetate $(60: 40, v / v)$ adjusted to $\mathrm{pH} 5.5$. It was filtered through a $\mathrm{MS}^{\circledR}$-nylon membrane filter (pore size $0.45 \mu \mathrm{m}$, diameter $4.7 \mathrm{~cm}$, Membrane Solutions, USA) and degassed before use. The flow rate was $0.8 \mathrm{~mL} / \mathrm{min}$, and the detection wavelengths were at 240 and $220 \mathrm{~nm}$, for LTZ and PLB, respectively. All experiments were performed at room temperature $\left(25 \pm 1{ }^{\circ} \mathrm{C}\right)$.

\section{Stock Standard and Working Solutions Preparation}

LTZ and PLB Stock Solutions Preparation. Primary LTZ stock solutions was prepared for use as standards and quality controls (QCs) at a concentration of $100 \mu \mathrm{g} / \mathrm{mL}$ by dissolving $5.0 \mathrm{mg}$ of LTZ in a very small volume of dimethyl sulfoxide (DMSO, 10 drops); then, the stock solution was diluted with ultrapure water to obtain a final concentration of $100 \mu \mathrm{g} / \mathrm{mL}$. Primary stock solutions of PLB were prepared by dissolving $5.0 \mathrm{mg}$ PLB in $0.5 \mathrm{~mL}$ ultrapure water at $\mathrm{pH}=4.0$ (by adding acetic acid); then, the stock was diluted to $100 \mu \mathrm{g} / \mathrm{mL}$ with ultrapure water.

LTZ and PLB Working Solutions Preparation. Working standard solutions of LTZ and PLB were prepared by suitably diluting the above-mentioned stock solutions. The prepared solutions were observed to be stable for 1 month when kept at 2-8 ${ }^{\circ} \mathrm{C}$, and there was no proof of degradation of LTZ and PLB seen in the chromatograms during this term.

IS Stock and Working Solutions Preparation. An IS was utilized to help measurement of an analyte by adjusting for loss at any point of the analysis, including losses related to plasma impacts. Numerous drugs such as caffeine, tipiracil, and paracetamol were tried, and paracetamol was observed to be the most agreeable IS. A primary stock solution of IS was prepared by dissolving $10 \mathrm{mg}$ of PAR in $100 \mathrm{~mL}$ of warm ultrapure water in a $100-\mathrm{mL}$ volumetric flask $(100 \mu \mathrm{g} / \mathrm{mL})$. Working standard solutions were then prepared by suitably diluting the above-mentioned stock solution.

Preparation of Spiked Rat Plasma and Assay Method. Simple protein precipitation was used to obtain samples free from endogenous components, which is essential for increasing recovery and minimizing matrix effects in HPLCPDA. Different precipitating solvents, such as methanol, ethanol, and acetonitrile, were tested. Acetonitrile proved to be the most suitable for removing endogenous components and obtaining clean plasma samples leading to acceptable 
matrix effects and recoveries; thus, it was used in the protein precipitation step [56]. Before analysis, the rat plasma samples were defrosted at room temperature. Fifty microliters of rat plasma was aliquoted in a 1.5-mL Eppendorf tube, spiked with $50 \mu \mathrm{L}$ of the working IS solution at $1000 \mathrm{ng} / \mathrm{mL}$ and appropriate aliquots of drug standard solution to give the required concentrations. Each tube was completed to volume of $0.5 \mathrm{~mL}$ with deionized water, vortexed for $30 \mathrm{~s}$, and then mixed with $0.5 \mathrm{~mL}$ of acetonitrile for deproteinization [56]. The tubes were subsequently vortexed at high speed for $1 \mathrm{~min}$ and centrifuged at $6000 \mathrm{rpm}$ for $30 \mathrm{~min}$. The supernatants from each tube were loaded into an autosampler tray, and $20 \mu \mathrm{L}$ of it were injected (in triplicate) into the HPLC system for analysis under the optimized chromatographic conditions. Blank experiments were run in parallel. Peak area ratios (D/IS) were plotted versus the concentrations of LTZ and PLB [57].

\section{Construction of Calibration Curves}

Standards and Quality Control (QC) Samples. Drug-free rat plasma samples spiked with predetermined amounts of LTZ and PLB, along with the IS, were utilized to construct plasma-based calibration curves. Nine spiked samples with different concentrations $(10,20,30,50,100,200,300,400$, 500 , and $600 \mathrm{ng} / \mathrm{mL}$ for LTZ and PLB) were prepared by adding appropriate aliquots of drug standard solutions into plasma. The QC samples were prepared at concentrations of $10 \mathrm{ng} / \mathrm{mL}$ (lower limit of quantification [LLOQ]), $30 \mathrm{ng} / \mathrm{mL}$ (low), $300 \mathrm{ng} / \mathrm{mL}$ (medium), and $600 \mathrm{ng} / \mathrm{mL}$ (high) for LTZ and PLB, which were also prepared and processed following the method above.

Validation of Method. Based on the FDA guidelines for bioanalytical methods [58], the proposed method was validated for specificity, linearity, lower limits of detection (LLOD), lower limits of quantification (LLOQ), accuracy, precision, \%extraction recovery, dilution integrity, matrix effects (ion suppression/enhancement), and stability.

Specificity. LTZ, PLB, and IS specificities were estimated by comparing the chromatograms gained from 6 batches of the blank plasma and samples with those of plasma spiked with low concentrations equivalent to the LLOQs of both studied drugs and IS. The peak area ratios observed at the PLB and LTZ retention times in each situation were compared to assess the specificity of each signal.

Linearity. The linearity of the assay was evaluated by constructing calibration curve in the plasma spiked with 9 different drug concentrations in the interval of $10-600 \mathrm{ng} / \mathrm{mL}$ for LTZ and PLB, along with $50 \mu \mathrm{L}$ of the IS (1000 ng/mL). Regression analysis was applied to the curve, which was constructed by plotting peak area ratios of LTZ and PLB to that of IS versus the concentrations of the spiked samples.

LLOQ and LLOD. The LLOQ and LLOD are the LTZ and PLB concentrations that give an analytical response of at least 10 times and 3 times the blank signal, respectively. Additionally, analytical responses at the LLOQ should produce reasonable accuracy and precision within $\pm 20 \%$.

\%Extraction Recovery. At 4 different QC levels, namely, very low LLOQ (10 $\mathrm{ng} / \mathrm{mL})$, low $(30 \mathrm{ng} / \mathrm{mL})$, medium (300 ng/mL), and high $(600 \mathrm{ng} / \mathrm{mL})$ for LTZ and PLB, the \%extraction recovery of LTZ and PLB from plasma samples was evaluated. The peak area obtained from plasma samples spiked pre-extraction is compared to those spiked post-extraction with the same nominal concentration level $(n=6)$. The extraction recovery of IS was also determined at the same concentration used in the actual analysis.

Matrix Effect. Matrix effect was measured in this assay by performing the same process for assessment of the extraction recovery, except the comparison of samples at 4 different concentrations with and without plasma.
Precision and Accuracy. Precision and accuracy were assessed at two levels, intra-day (on the same day, $n=6$ ) and inter-day (on 3 consecutive days, $n=18$ ). These assessments were performed by analyzing 4 QC samples of PLB and LTZ prepared at LLOQ, low, medium, and high concentrations, as described in the extraction recovery section. For each solution, the ratio of PLB and LTZ peak area to that of IS was used to calculate the actual analyte concentration by substitution into the regression equations, and these values were compared with the nominal values. Relative standard deviation (\% RSD) was used to evaluate the intra-day and inter-day precision. To assess accuracy, relative error $(\mathrm{Er} \%)$ was calculated from the following formula: $\mathrm{Er} \%=$ (assayed value/nominal value) $\times 100 \%$.

Dilution Integrity. The dilution of highly concentrated plasma samples, with concentrations beyond the linear range of the proposed assay, was evaluated for its effect on PLB and LTZ recoveries. Plasma samples spiked with high concentrations of PLB and LTZ (1000 ng/mL) were used, following dilution (1:2 and 1:4) with blank plasma samples. The diluted samples were then treated as described under "Sample preparation".

Stability Studies. QC samples spiked at 4 concentrations of PLB and LTZ were analyzed $(n=6)$ in order to assess drug stability in the plasma. Stability testing was performed by exposing the QC plasma samples to different conditions: autosampler stability $\left(10^{\circ} \mathrm{C}, 56 \mathrm{~h}\right)$ is the stability of the analyte in the processed sample under the conditions in the autosampler, short-term stability $\left(25^{\circ} \mathrm{C}, 6 \mathrm{~h}\right)$ or bench-top stability is the stability of an analyte in a matrix under conditions of sample handling during sample processing, extract stability $\left(10^{\circ} \mathrm{C}\right.$, $48 \mathrm{~h}$ ) assesses the degradation of the processed sample relative to the starting material, and freeze-thaw stability $\left(-30{ }^{\circ} \mathrm{C}, 3\right.$ cycles) $)^{\mathrm{e}}$ refers to the stability of the analyte in the matrix upon freezing and thawing and was assessed by freezing the plasma samples at approximately $-30{ }^{\circ} \mathrm{C}$ and then thawing at room temperature for 3 cycles. Moreover, long-term stability $\left(-30{ }^{\circ} \mathrm{C}\right.$ for 30 days) assesses the degradation of an analyte in the matrix relative to the starting material after periods of frozen storage. For each sample, PLB and LTZ concentrations were compared to their nominal concentrations to calculate the \%recovery.

\section{Pharmacokinetic Study of LTZ and PLB in Rats}

The Study Protocols. Ten to 12-week-old adult male Swiss albino rats weighing $250 \pm 25 \mathrm{~g}$ were obtained from the Experimental Animal Care Center, College of Pharmacy, King Saud University. The animals were acclimated in our laboratory for 2 days under standard conditions of humidity, temperature $\left(25 \pm 2{ }^{\circ} \mathrm{C}\right)$, and light $(12 \mathrm{~h} \mathrm{light} / 12 \mathrm{~h}$ dark). Rats were fed with a standard rat pellet diet and had free access to water. All animal procedures employed complied with the standards set forth in the guidelines for care and use of experimental animals by the Committee for Purpose of Supervision of Experiments on Animals (CPCSEA) [59] and the National Institutes of Health (NIH) protocol [60]. The study protocol was approved by the Animal Ethics Committee of Pharmacology Department, College of Pharmacy, King Saud University, Kingdom of Saudi Arabia. After 2 days of acclimation, the rats were randomly divided into 2 groups consisting of 4 rats each. First group of rats were intraperitoneally injected with a combination of LTZ $2 \mathrm{mg} / \mathrm{kg}$ and PLB $25 \mathrm{mg} / \mathrm{kg}$, while saline was administered to the remaining group of rats to enable the acquisition of control rat plasma. The injected volume was $0.01 \mathrm{~mL} / \mathrm{g}$ body weight. Blood samples from animals treated with combination of LTZ and PLB were withdrawn by a retro-orbital technique after sacrificing groups of rats at $0.5,1$, $2,4,6,8,10,12$, and $24 \mathrm{~h}$ after exposure to combination of 
LTZ and PLB. At a specific time, blood samples were collected from each group in a heparin tube (anticoagulant); then, the plasma samples were separated from blood by centrifugation $\left(3000 \mathrm{rpm}\right.$ at $4{ }^{\circ} \mathrm{C}$ ) for $10 \mathrm{~min}$ and then stored at $-2{ }^{\circ} \mathrm{C}$ until analysis. Fifty-microliter aliquots of plasma samples were transferred to a series of $1.5-\mathrm{mL}$ Eppendorf tubes and analyzed as described above.

Ethics Statement. The study protocol was approved by the local Research Ethics Committee of Animal Experiments, King Saud University, Riyadh, Saudi Arabia. All experiments were carried out in accordance with the ethical guidelines for experimental studies with animals as per the local Research Ethics committee, King Saud University (Ref. No.: KSU-SE18-18).

Pharmacokinetic Computations. The LTZ and PLB plasma concentrations were analyzed as a function of time by PK Solver 2.0 Add-in, Excel 2010. The pharmacokinetic parameters were computed based on a noncompartmental analysis (NCA) technique. Statistical comparisons were made between the control group and the treated groups using analysis of variance (ANOVA), followed by Dunnett's test at $\alpha=0.05$.

\section{Results and Discussion}

Optimization of Chromatographic Conditions. The new simple and accurate HPLC-PDA method for the determination of LTZ and PLB in spiked rat plasma was developed. The chromatographic conditions used for isocratic separation resulted in a good profile for the analytes in the plasma when the C18 $(4.6 \mathrm{~mm} \times 150 \mathrm{~mm}, 3.5 \mu \mathrm{m})$ column was used. Different mobile phase ratios were tested to minimize the retention times of the analytes, optimize the separation, and improve peak symmetry. High methanol percentage resulted in shorter retention times of LTZ and
PLB, but with low resolution between the two drugs. Decreasing the percentage of methanol improved the resolution with reasonable retention times. The best results with respect to peak symmetry, column efficiency, and resolution were obtained using methanol-30 $\mathrm{mM}$ ammonium acetate buffer $(\mathrm{pH} 5.5 ; 60: 40, v / v)$ as the mobile phase. The $\mathrm{pH}$ of the mobile phase was adjusted with acetic acid to $\mathrm{pH}$ 5.5. LTZ and PLB were detected at 240 and $220 \mathrm{~nm}$, respectively. Analytical wavelengths for LTZ and PLB were selected based on the absorption maxima occurring in the spectra obtained (Figure 2). Furthermore, at selected wavelengths, no endogenous interfering peaks from the empty matrix were recorded. LTZ and PLB were successfully extracted from interfering plasma using an acetonitrile-based deproteinization procedure with good recoveries. Due to high recovery with good validation results, paracetamol was selected as an internal standard.

System Suitability. Chromatographic separation using the proposed HPLC-PDA method was performed to evaluate various chromatographic parameters: the capacity factor $K$, the selectivity factor $(\alpha)$, and the resolution (Rs) between 2 consecutive peaks. Figure 3 shows a representative chromatogram that corresponds to the chromatographic separation of the studied drugs obtained from spiked rat plasma. The peaks of LTZ, PLB, and paracetamol (IS) were well resolved, with retention times of $3.51 \pm 0.09$, $4.51 \pm 0.08$, and $2.62 \pm 0.06 \mathrm{~min}$, respectively. Analysis was achieved within $5 \mathrm{~min}$. The values of the suitability parameters are presented in Table 1. In conclusion, the method developed in this study, using the mobile phase consisting of methanol-30 $\mathrm{mM}$ ammonium acetate buffer adjusted to $\mathrm{pH} 5.5(60: 40, v / v)$ with a $\mathrm{C} 18 \quad(4.6 \mathrm{~mm}$ $\times 150 \mathrm{~mm}, 3.5 \mu \mathrm{m})$ column resulted in a satisfactory resolution $(R \mathrm{~s}=2.20)$ between PLB and LTZ and a selectivity factor $(\alpha)$ of 2.24 in a reasonable time of $<5 \mathrm{~min}$. Figure 3
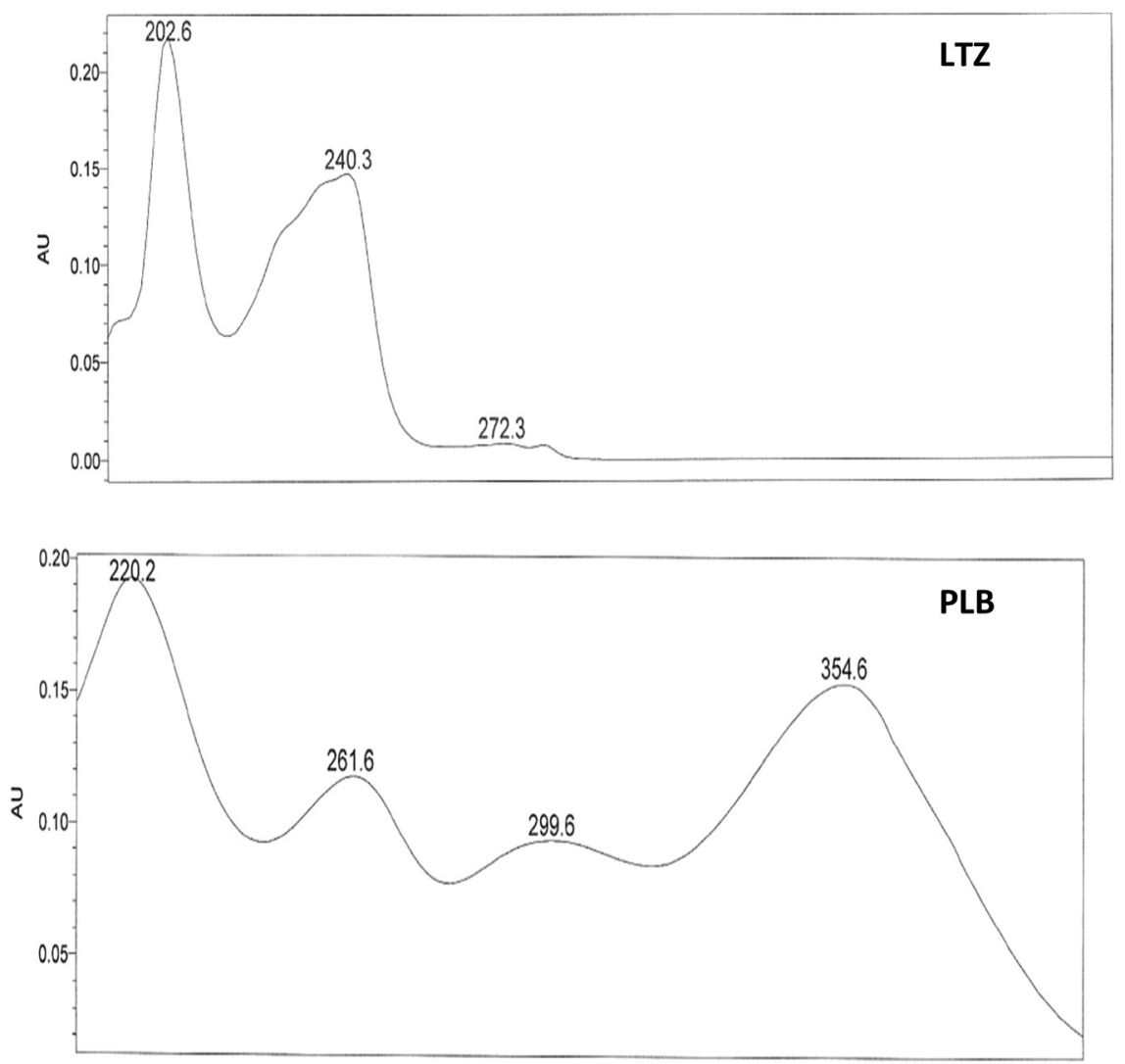

Figure 2. UV spectra of LTZ $\left(\lambda_{\max } 240\right)$ and PLB $\left(\lambda_{\max } 220\right)$ recorded with a PDA detector 


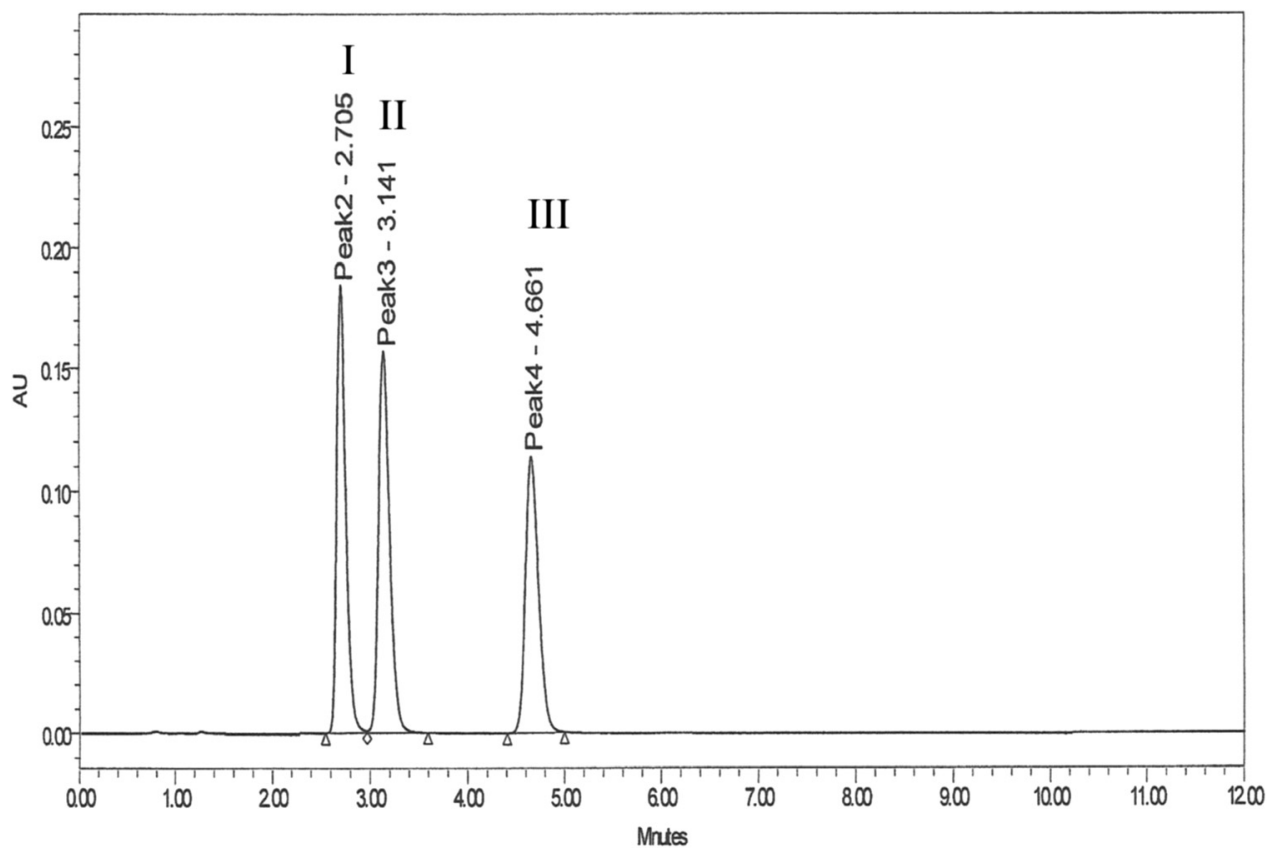

Figure 3. Chromatogram of the standard mixture of LTZ (600 ng/mL) (peak III) and PLB (600 ng/mL) (peak II) along with the IS (1000 ng/mL) (peak I) spiked in rat plasma

shows a typical chromatogram of the studied drugs in spiked plasma under the optimized chromatographic conditions. The proposed method offers high sensitivity, since $10 \mathrm{ng} / \mathrm{mL}$ of PLB and LTZ were accurately determined.

\section{Method Validation}

Specificity of the Method. To evaluate the specificity of the developed HPLC-PDA method and to detect interferences, rat plasma samples spiked with $10 \mathrm{ng} / \mathrm{mL}$ of LTZ and PLB and $1000 \mathrm{ng} / \mathrm{mL}$ of IS, in addition to blank plasma samples, were analyzed. Figure $4(a, b)$ represents chromatograms of blank plasma samples and plasma samples spiked with the studied drugs and the IS. The peaks of LTZ, PLB, and the IS were well resolved, with retention times of $3.51 \pm 0.09$, $4.51 \pm 0.08$, and $2.62 \pm 0.06 \mathrm{~min}$, respectively. No endogenous peak from the plasma was found to interfere with the elution of the studied drugs. Deproteinization of the plasma samples was sufficient to isolate LTZ, PLB, and the IS without any interfering endogenous peaks at 240 and $220 \mathrm{~nm}$, therefore proving the specificity of the developed method.

Linearity and LLOD and LLOQ. The linarites of the method for determination of LTZ and PLB were evaluated by spiking these drugs into blank plasma. Calibrations standards were extracted at each concentration and analyzed. Calibration curves were prepared for each drug, based on the ratio of the peak area signal from the drug to that of paracetamol (IS) vs. the theoretical concentration. Least squares linear regression

Table 1. System suitability parameters for LTZ, PLB, and IS in spiked rat plasma

\begin{tabular}{lccc}
\hline Parameters & LTZ & PLB & IS \\
\hline$R s^{a}$ & 1.73 & 2.20 & $\mathrm{f}$ \\
$\alpha^{b}$ & 1.41 & 2.24 & $\mathrm{f}$ \\
$k^{c}$ & 2.62 & 3.51 & $\mathrm{f}$ \\
$t_{\mathrm{R}}{ }^{d, e}$ & $3.51 \pm 0.09$ & $4.51 \pm 0.08$ & $2.62 \pm 0.06$ \\
${ }^{a}$ Resolution factor, calculated as Rs $=\left(t_{\mathrm{R} 2}-t_{\mathrm{R} 1}\right) / 0.5\left(w_{1}+w_{2}\right)$, where \\
$t_{\mathrm{R} 2}$ and $t_{\mathrm{R} 1}$ are the retention time of second and first peaks, and $w_{1}$ and \\
${ }^{w_{2} \text { are the peak width of first and second peaks. }}$ \\
${ }^{b}$ Selectivity factor, calculated as $k_{2} / k_{1}$. \\
${ }^{c}$ Capacity factor, calculated as $\left(t_{\mathrm{R}}-t_{0}\right) / t_{0}$. \\
${ }^{d}$ Retention time. \\
${ }^{e}$ Mean \pm SD $(n=10)$. \\
${ }^{f}$ Not calculated. \\
\hline
\end{tabular}

analysis of the data gave slope, intercept, and correlation coefficients data (Table 2). The concentration range corresponding to a linear response was found to be $10-600 \mathrm{ng} / \mathrm{mL}$ for LTZ and PLB. The values of the correlation coefficients and small intercepts indicate that the calibration graph is highly linear. Small values of the standard deviation of residuals $\left(S_{y / x}\right)$, of the intercept $\left(S_{\mathrm{a}}\right)$, and of the slope $\left(S_{\mathrm{b}}\right)$ indicate low scatter in points around the calibration [57]. As seen in Table 3, the LLODs in plasma were found to be $5 \mathrm{ng} / \mathrm{mL}$ for LTZ and PLB. The LLOQ for each calibration graph was $10 \mathrm{ng} / \mathrm{mL}$ for LTZ and PLB. These detection limits confirm that it is possible to determine LTZ and PLB in blood samples from patients treated with these drugs.

\%Extraction Recovery. The extraction recovery of LTZ and PLB from plasma samples was assessed using QC plasma samples spiked with LTZ and PLB at various concentrations, specifically very low LLOQ $(10 \mathrm{ng} / \mathrm{mL})$, low $(30 \mathrm{ng} / \mathrm{mL})$, medium $(300 \mathrm{ng} / \mathrm{mL})$, and high $(600 \mathrm{ng} / \mathrm{mL})$ for PLB and LTZ. The mean \%recovery was not less than $91.24 \pm 3.05 \%$ for LTZ and $90.85 \pm 2.68$ for PLB, indicating that the extraction recovery for all analytes from plasma samples was good. These results are summarized in Table 4.

Accuracy and Precision. The results obtained were validated for precision by measuring both the intra-day and interday variances of the peak areas of LTZ and PLB. All accuracy and precision values, including the LLOQ, were within the considered acceptable limits [59]. The results presented in Table 5 indicate that the intra-day relative standard deviation, $\% R S D$, ranged between 1.72 and $2.47 \%$ for LTZ and between 0.29 and $1.66 \%$ for PLB, while the inter-day \%RSD values ranged between 1.34 and $2.99 \%$ for LTZ and between 0.58 and $2.46 \%$ for PLB. The overall recovery (\%) of LTZ from in vitro rat plasma ranged from 96.26 to $98.88 \%$, and that for PLB ranged from 94.67 to $99.15 \%$ (Table 5). The repeatability of the retention times was also investigated. Since many factors may affect the repeatability of the retention time in HPLC, the experimental conditions were strictly controlled. The standard deviation values of the retention time of LTZ, PLB, and IS for 10 replicates were $3.51 \pm 0.09,4.51 \pm 0.08$, and $2.62 \pm 0.06$, respectively, which showed that there was fair repeatability. 
a

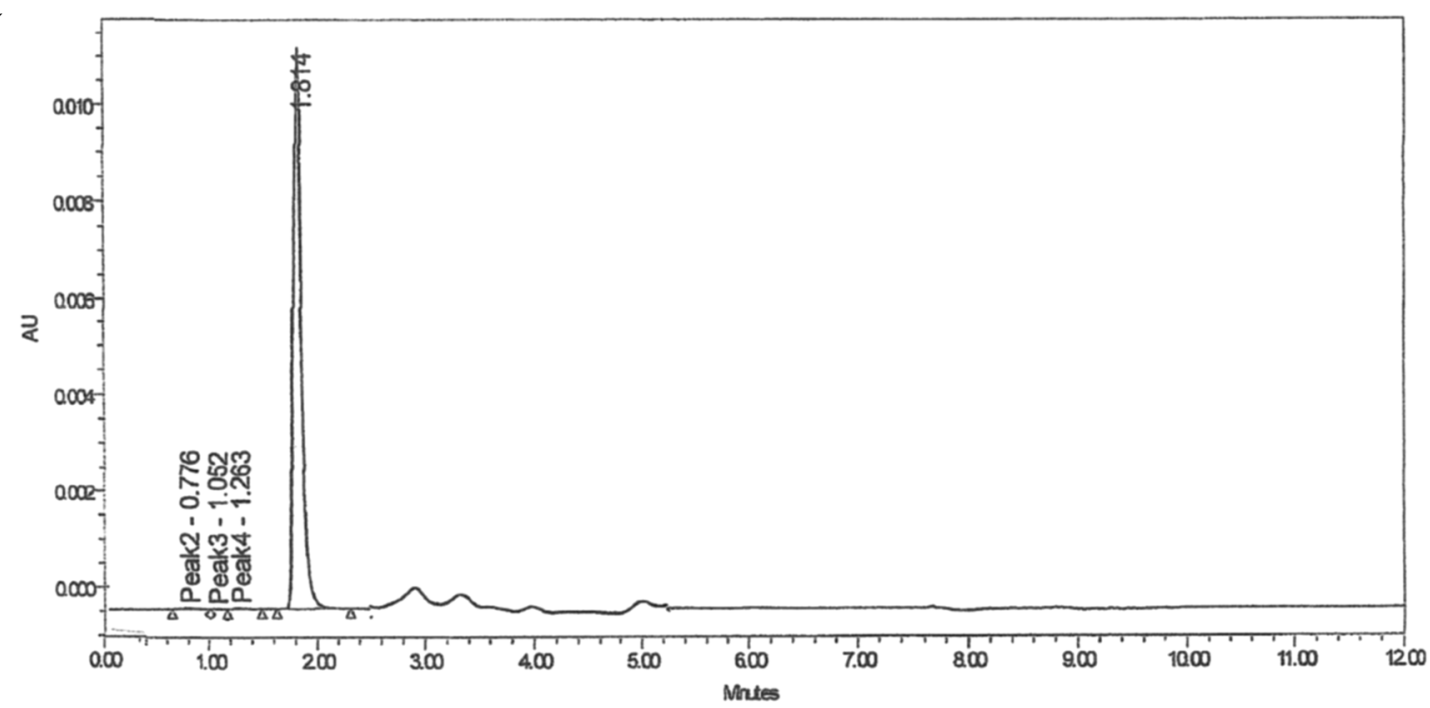

b

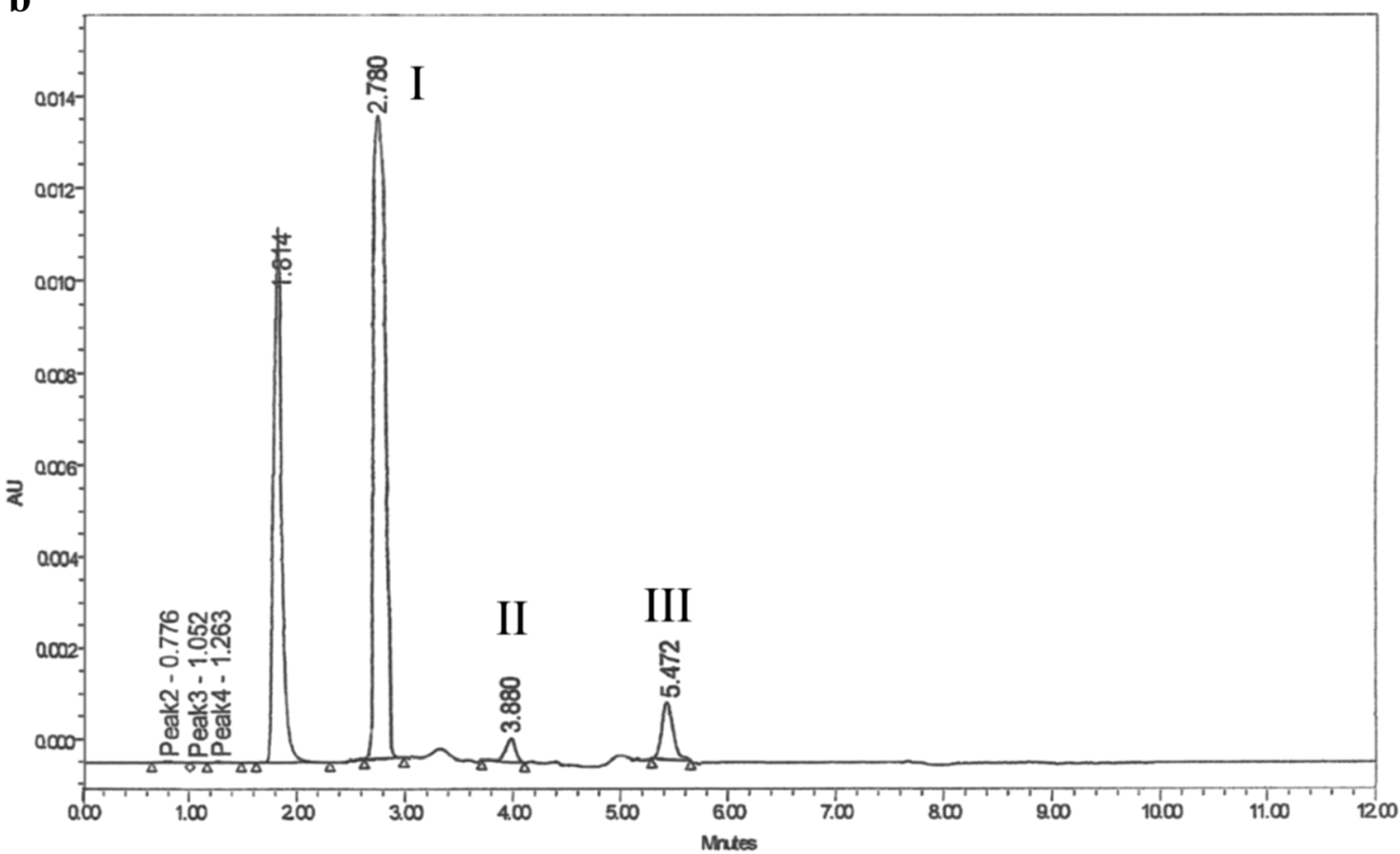

Figure 4. (a) Chromatogram of blank rat plasma. (b) Chromatogram of the standard mixture of LTZ (10 ng/mL) (peak III) and PLB (10 ng/mL) (peak II), along with the IS $(100 \mathrm{ng} / \mathrm{mL})$ (peak I) spiked in rat plasma

Table 2. Statistical data of the regression equation for the calibration of LTZ and PLB obtained from rat plasma by the proposed HPLC-PDA method

\begin{tabular}{lcc}
\hline Parameters & LTZ & PLB \\
\hline Linear range $(\mathrm{ng} / \mathrm{mL})$ & $10-600$ & $10-600$ \\
Regression equation $(n=3)$, & $Y=0.194 X$ & $Y=0.10 X$ \\
$Y^{a}=B X^{b}+A$ & +0.134 & -0.0088 \\
Correlation coefficient $(r)$ & 0.9996 & 0.9994 \\
Determination coefficient $\left(r^{2}\right)$ & 0.9995 & 0.9992 \\
$S_{y / x}$ & 1.032 & 0.636 \\
$S_{\mathrm{a}}$ & 0.434 & -0.0088 \\
$S_{\mathrm{b}}$ & 0.0015 & 0.00093 \\
$F$ & 16532.6 & 11634.32 \\
Degrees of freedom & 9 & 9 \\
Residual sum of squares & 9.59 & 3.64 \\
Regression sum of squares & 17620.34 & 4699.76 \\
LLOD $(\mathrm{ng} / \mathrm{mL})^{c}$ & 5 & 7 \\
LLOQ (ng/mL) & 10 & \\
$\quad{ }^{a}$ Represents the peak area ratio (D/IS). & \\
${ }^{b}$ Represents the concentration of the analyte (ng/mL). & \\
${ }^{c} S / N=3$. & & \\
${ }^{c} S / N=10$. & & \\
\hline
\end{tabular}

Table 3. Evaluation of the intra-day and inter-day accuracy and precision for the LLOQ and LLOD determination of LTZ and PLB in rat plasma by the proposed HPLC-PDA

\begin{tabular}{|c|c|c|c|c|c|}
\hline Drug & $\begin{array}{l}\text { Actual cc } \\
(\mathrm{ng} / \mathrm{mI}\end{array}$ & & $\begin{array}{l}\text { Measured conc. } \\
(\mathrm{ng} / \mathrm{mL}) \pm \mathrm{SD}^{b}\end{array}$ & \%Recovery ${ }^{c}$ & $\overline{\%} \overline{\% S D^{d}}$ \\
\hline$\overline{\text { LTZ }}$ & Intra-day & 5 & $4.33 \pm 0.41$ & 86.60 & 9.47 \\
\hline & & 10 & $9.54 \pm 0.79$ & 95.40 & 8.28 \\
\hline & Inter-day & 5 & $0.41 \pm 0.42$ & 86.20 & 9.75 \\
\hline & & 10 & $9.53 \pm 9.77$ & 95.30 & 8.08 \\
\hline PLB & Intra-day & 7 & $6.32 \pm 0.50$ & 90.29 & 7.91 \\
\hline & & 10 & $9.67 \pm 0.70$ & 96.70 & 7.24 \\
\hline & Inter-day & 7 & $6.30 \pm 0.52$ & 90.00 & 8.25 \\
\hline & & 10 & $9.66 \pm 0.68$ & 96.60 & 7.04 \\
\hline$d_{0} / 0$ & $\begin{array}{l}\text { entration. } \\
\text { covery bas } \\
\text { covery } \\
D=(S D / m\end{array}$ & $\begin{array}{l}\text { on } n \\
\text { asure }\end{array}$ & 6. & ncentration) & 00. \\
\hline
\end{tabular}

Matrix Effects. Based on the FDA guidelines for bioanalytical methods, the estimation of matrix effects comprises a remarkable and essential part of the validation of the 
Table 4. The mean of \%recovery extraction of LTZ and PLB with the IS extracted from rat plasma by acetonitrile-based deproteinization $(n=3)$

\begin{tabular}{lcccccc}
\hline LTZ & & & & \multicolumn{2}{c}{ PLB } \\
\cline { 1 - 2 } \cline { 5 - 6 } $\begin{array}{l}\text { Actual } \\
\text { amount } \\
(\mathrm{ng} / \mathrm{mL})\end{array}$ & $\begin{array}{c}\text { Amount } \\
\text { recovered } \\
(\mathrm{ng} / \mathrm{mL})\end{array}$ & \%Recovery & & $\begin{array}{c}\text { Actual } \\
\text { amount } \\
(\mathrm{ng} / \mathrm{mL})\end{array}$ & $\begin{array}{c}\text { Amount } \\
\text { recovered } \\
(\mathrm{ng} / \mathrm{mL})\end{array}$ & \%Recovery \\
\hline 10 & 8.76 & 87.60 & & 10 & 8.88 & 88.80 \\
30 & 27.09 & 90.30 & & 30 & 26.87 & 89.57 \\
300 & 277.56 & 92.52 & & 300 & 269.05 & 89.68 \\
600 & 563.00 & 93.83 & & 600 & 558.98 & 93.16 \\
Mean & & 91.06 & & Mean & & 90.30 \\
SD & & 2.73 & & SD & & 1.95 \\
\hline
\end{tabular}

Table 5. Accuracy and precision data obtained when the proposed method was applied to the quality control samples of in vitro rat plasma containing LTZ and PLB

\begin{tabular}{ccccccc}
\hline Analyte & $\begin{array}{c}\text { Actual } \\
\text { conc. } \\
(\mathrm{ng} / \mathrm{mL})\end{array}$ & $\begin{array}{c}\text { Experimental } \\
\text { conc. } \\
(\mathrm{ng} / \mathrm{mL})\end{array}$ & $\begin{array}{c}\text { RSD } \\
(\%)^{a}\end{array}$ & $\begin{array}{c}\text { Recovery } \\
(\%)\end{array}$ & $\begin{array}{c}\text { Error } \\
(\%)^{b}\end{array}$ \\
\hline Intra-day $^{c}$ & LTZ & 10 & $9.54 \pm 0.89$ & 9.33 & 95.40 & -4.60 \\
& & 30 & $29.04 \pm 2.66$ & 9.16 & 96.80 & -3.20 \\
& & 300 & $293.88 \pm 3.21$ & 1.09 & 97.96 & -2.04 \\
& & 600 & $589.89 \pm 7.43$ & 1.26 & 98.31 & -1.69 \\
& & 10 & $9.67 \pm 0.71$ & 7.34 & 96.70 & -3.30 \\
Inter-day $^{d}$ & LTZ & 30 & $29.68 \pm 2.46$ & 8.29 & 98.93 & -1.07 \\
& & 300 & $297.03 \pm 9.88$ & 3.33 & 99.01 & -0.99 \\
& & 600 & $596.44 \pm 16.77$ & 2.81 & 99.41 & -0.59 \\
& & 30 & $29.00 \pm 2.86$ & 9.86 & 96.67 & -3.33 \\
& & 300 & $293.87 \pm 3.11$ & 1.06 & 97.96 & -2.04 \\
& & 600 & $589.79 \pm 7.23$ & 1.23 & 98.30 & -1.70 \\
& & 10 & $9.66 \pm 0.70$ & 7.45 & 96.60 & -3.40 \\
& & 30 & $29.60 \pm 2.85$ & 9.61 & 98.87 & -1.13 \\
& & 600 & $297.00 \pm 10.00$ & 3.37 & 99.00 & -1.00 \\
& & 600 & $596.50 \pm 20.33$ & 3.41 & 99.42 & -0.58
\end{tabular}

${ }^{a}$ Expressed as \% RSD: (SD/mean) $\times 100$.

${ }^{b}$ Calculated as ([found conc. - actual conc. $] /$ actual conc. $) \times 100$.

${ }^{c}$ Mean \pm SD based on $n=3$.

${ }^{d}$ Mean \pm SD based on $n=9$.

quantitative analysis of drugs in plasma samples [59]. Matrix effects can result in co-elution of endogenous matter that exists in biological samples. This may produce a signal in the chromatogram of the target analyte, which can obviously decrease or increase the response of the analyte to affect the sensitivity, accuracy, and precision of the method. The matrix effect was measured in this study by performing the same process used for assessment of extraction recovery, but comparing the results obtained at 4 different drug concentration levels with and without the added plasma. As seen in Table 6, the mean matrix effect values at 4 concentrations of LTZ and PLB were more than $88.17 \%$, and the calculated relative standard deviations of the drugs were less than $11.83 \%$. This confirms that the proposed method was practically free from matrix effects for the determination of LTZ and PLB in rat plasma. Because the matrix effect was low, trace analysis of LTZ and PLB in plasma samples is possible using the proposed method.

Dilution Integrity. The effect of diluting plasma samples containing very high analyte concentrations was assessed by a dilution integrity test. Plasma samples that contained high concentrations of each of the studied drugs $(1000 \mathrm{ng} / \mathrm{mL}$ for both LTZ and PLB) were diluted with rat plasma (1:2 and 1:4) and then analyzed by the proposed method. The mean percent relative standard deviation ( $\% \pm \mathrm{RSD})$ for each situation was calculated and is shown in Table 7 . All $\% \pm$ RSD values were within $\pm 15 \%$ of the nominal values, which demonstrates the integrity of the analysis after dilution of the plasma samples
Table 6. Evaluation of the matrix effect for the determination of LTZ and PLB in rat plasma by the proposed HPLC-PDA

\begin{tabular}{lccc}
\hline DRUG & $\begin{array}{c}\text { Concentration } \\
(\mathrm{ng} / \mathrm{mL})\end{array}$ & $\begin{array}{c}\text { Mean recovery } \\
(\%) \pm \mathrm{RSD}^{a}\end{array}$ & $E_{\mathrm{r}}(\%)^{b}$ \\
\hline LTZ & 10 & $91.77 \pm 5.60$ & 8.23 \\
& 30 & $93.15 \pm 6.34$ & 6.95 \\
& 300 & $96.13 \pm 3.24$ & 3.97 \\
& 600 & $98.55 \pm 2.13$ & 1.45 \\
$\mathrm{PLB}$ & 10 & $88.86 \pm 2.19$ & 10.14 \\
& 30 & $90.63 \pm 0.58$ & 9.37 \\
& 300 & $91.00 \pm 1.29$ & 9.00 \\
& 600 & $94.42 \pm 0.36$ & 5.58 \\
${ }^{a} \mathrm{RSD}$ of 6 determination. & \\
${ }^{b} E_{\mathrm{r}}(\%)$ : percentage relative error. & \\
\hline
\end{tabular}

Table 7. Dilution integrity LTZ and PLB in rat plasma by the proposed HPLC-PDA method $(n=3)$

\begin{tabular}{lccc}
\hline Drugs & $\begin{array}{c}\text { Dilution } \\
\text { fold }\end{array}$ & $\begin{array}{c}\text { Mean recovery } \\
(\%) \pm \% R S D\end{array}$ & $E_{\mathrm{r}}(\%)^{a}$ \\
\hline LTZ & $1: 2$ & $101.77 \pm 5.56$ & +1.77 \\
& $1: 4$ & $103.87 \pm 9.61$ & +3.87 \\
PLB & $1: 2$ & $106.89 \pm 3.82$ & +6.89 \\
& $1: 4$ & $103.97 \pm-2.67$ & +3.97 \\
${ }^{a} E_{\mathrm{r}}(\%):$ percentage relative error. & & \\
\hline
\end{tabular}

up to 4 times. Sample dilution should not affect the accuracy and precision [59].

Stability. Quality control samples containing LTZ and PLB were used for stability experiments. Stability was assessed under various conditions. The deviations of the main test responses for LTZ and PLB were within $\pm 5 \%$ of the appropriate controls. No evidence of degradation was observed during sample processing and storage for at least 1 month in a freezer at $4{ }^{\circ} \mathrm{C}$. No effect on quantification of LTZ and PLB was observed for the short-term stability on the frozen samples kept at room temperature. The results of these studies as shown in Table 8 suggest that the rat plasma samples containing LTZ and PLB can be handled under normal laboratory conditions without incurring any significant loss of these drugs.

Assay Robustness. The robustness of an analytical procedure refers to its ability to remain unaffected by small and deliberate variations in method parameters and provides an indication of its reliability for routine analysis [59]. The robustness of the method was assessed using a one-variable-at-a-time (OVAT) approach at 3levels $( \pm 0.2 \%)$ [59]. Robustness was statistically analyzed using the peak area, migration time, and resolution of LTZ, PLB, and paracetamol (IS). The OVAT procedure varies the levels of a given parameter while keeping the other factors at optimal levels. The studied parameters were the flow rate, the ratio of the mobile phase, the $\mathrm{pH}$, and the maximum wavelength. The results of robustness for different parameters are expressed in $\% R S D(n=3)$ as seen in Table 9. No significant variations in accuracy and precision (retention time; peak area) were found in the tested range, which indicates that this method is robust (RSD values ranged from 0.15 to $3.95 \%$ ).

Pharmacokinetics Study. The optimized method was applied to pharmacokinetics evaluation of LTZ combined with PLB in rats. The concentrations of LTZ and PLB in rat plasma were determined at $0,0.5,1,2,4,6,8,10,12$, and $24 \mathrm{~h}$ after dosing by the optimized HPLC-PDA method. All of the peaks were completely resolved at the therapeutic concentrations of LTZ and PLB. After the determination of serum concentrations vs. time curves (AUC) were constructed for LTZ and PLB as shown in Figure 5, then the main parameters of the pharmacokinetics of LTZ and PLB were 
Table 8. Stability data of LTZ and PLB in rat plasma under various stability conditions $(n=3)$ by the proposed HPLC-PDA method

\begin{tabular}{ccccccc}
\hline Drug & $\begin{array}{c}\text { Conc } \\
(\mathrm{ng} / \mathrm{mL})\end{array}$ & $\begin{array}{c}\text { Autosampler stability } \\
\left(10^{\circ} \mathrm{C}, 56 \mathrm{~h}\right)^{b}\end{array}$ & $\begin{array}{c}\text { Short-term stability } \\
\left(25^{\circ} \mathrm{C}, 6 \mathrm{~h}\right)^{c}\end{array}$ & $\begin{array}{c}\text { Extract stability } \\
\left(10^{\circ} \mathrm{C}, 48 \mathrm{~h}\right)^{d}\end{array}$ & $\begin{array}{c}\text { Freeze-thaw stability } \\
\left(-30^{\circ} \mathrm{C}, 3 \text { cycles }\right)^{e}\end{array}$ & $\begin{array}{c}\text { long-term stability } \\
\left(-30^{\circ} \mathrm{C}, 30 \text { days }\right)^{f}\end{array}$ \\
\hline LTZ & 10 & $91.47 \pm 6.12$ & $91.67 \pm 1.20$ & $90.27 \pm 2.20$ & $90.97 \pm 3.30$ & $90.33 \pm 0.83$ \\
& 30 & $93.43 \pm 0.79$ & $91.77 \pm 1.14$ & $89.50 \pm 1.48$ & $89.33 \pm 1.41$ & $95.83 \pm 2.87$ \\
& 300 & $94.40 \pm 2.32$ & $92.25 \pm 1.20$ & $93.06 \pm 0.77$ & $91.00 \pm 1.37$ & $97.08 \pm 1.42$ \\
PLB & 600 & $96.79 \pm 0.89$ & $95.56 \pm 1.81$ & $95.89 \pm 1.74$ & $96.67 \pm 2.30$ & $97.41 \pm 1.19$ \\
& 10 & $89.43 \pm 1.45$ & $90.87 \pm 1.55$ & $89.07 \pm 2.36$ & $91.40 \pm 1.74$ & $92.47 \pm 1.39$ \\
& 30 & $93.86 \pm 2.49$ & $92.24 \pm 2.49$ & $93.33 \pm 3.33$ & $94.10 \pm 3.13$ & $92.61 \pm 0.73$ \\
& 300 & $97.04 \pm 0.86$ & $95.56 \pm 0.26$ & $95.28 \pm 0.33$ & $94.97 \pm 0.43$ & $95.58 \pm 1.61$ \\
& 600 & $94.69 \pm 0.25$ & $95.48 \pm 1.49$ & $94.69 \pm 2.68$ & $95.43 \pm 1.40$ & $94.90 \pm 0.30$
\end{tabular}

${ }^{a}$ RSD of 6 determination.

${ }^{b}$ Autosampler stability is the stability of the analyte in the processed sample under the conditions in the autosampler.

${ }^{c}$ Short-term or bench-top stability is the stability of an analyte in a matrix under conditions of sample handling during sample processing.

${ }^{d}$ Extract stability assesses the degradation of the processed sample relative to the starting material.

${ }^{e}$ Freeze-thaw stability refers to the stability of the analyte in the matrix upon freezing and thawing.

${ }^{f}$ Long-term stability assesses the degradation of an analyte in the matrix relative to the starting material after periods of frozen storage.

Table 9. The robustness of the method under different analytical conditions at 3 levels $(0, \pm 2 \%)$ presented as $\% R S D$ values

\begin{tabular}{|c|c|c|c|c|c|c|c|c|c|c|}
\hline \multirow[t]{2}{*}{ Parameters } & & \multicolumn{3}{|c|}{ On Peak Area } & \multicolumn{3}{|c|}{ On Retention times } & \multicolumn{3}{|c|}{ On Resolution } \\
\hline & & LTZ & PLB & IS & LTZ & PLB & IS & LTZ & PLB & IS \\
\hline \multirow[t]{3}{*}{ Flow rate } & 0.78 & 2.82 & 2.05 & 1.62 & 1.38 & 3.94 & 2.39 & 3.51 & 1.73 & - \\
\hline & 0.8 & 1.43 & 2.57 & 1.88 & 2.91 & 2.16 & 2.22 & 3.53 & 2.70 & - \\
\hline & 0.82 & 0.68 & 0.92 & 0.15 & 2.62 & 0.65 & 3.48 & 3.33 & 3.23 & - \\
\hline \multirow{3}{*}{ Ratio mobile phase } & $58: 42$ & 1.16 & 1.15 & 1.15 & 3.01 & 2.44 & 3.54 & 1.90 & 3.21 & - \\
\hline & $60: 40$ & 2.371 & 2.37 & 2.37 & 1.32 & 2.11 & 2.98 & 0.26 & 0.22 & - \\
\hline & $62: 38$ & 3.11 & 1.23 & 1.11 & 2.76 & 3.95 & 2.90 & 3.42 & 3.56 & - \\
\hline \multirow{2}{*}{$\mathrm{pH}$} & 5.5 & 0.98 & 1.51 & 0.65 & 0.88 & 1.03 & 0.17 & 0.70 & 0.93 & - \\
\hline & 5.6 & 0.66 & 0.94 & 0.43 & 0.87 & 1.21 & 0.54 & 0.79 & 0.92 & - \\
\hline \multirow[t]{3}{*}{$\lambda_{\max }$ of LTZ } & 238 & 3.02 & - & - & 0.16 & - & - & 0.45 & - & - \\
\hline & 240 & 2.99 & - & - & 1.02 & - & - & 0.67 & - & - \\
\hline & 242 & 3.41 & - & - & 0.44 & - & - & 0.79 & - & - \\
\hline \multirow[t]{3}{*}{$\lambda_{\max }$ of PLB } & 218 & - & 1.55 & - & - & 0.97 & - & - & 1.31 & - \\
\hline & 220 & - & 2.01 & - & - & 1.77 & - & - & 0.94 & - \\
\hline & 222 & - & 1.86 & - & - & 1.57 & - & - & 1.25 & - \\
\hline
\end{tabular}

calculated. The mean values of $T_{\max }$ and $C_{\max }$ were $6 \mathrm{~h}$ and $266.96 \pm 21.23 \mathrm{ng} / \mathrm{mL}$ for LTZ and $4 \mathrm{~h}$ and $508.75 \pm 61.56 \mathrm{ng} / \mathrm{mL}$ for PLB, respectively, as represented in Table 10. The result of the pharmacokinetics of LTZ was similar to results reported on LTZ analysis by fluorescence [33-36] or mass detection [37-45] alone and was more sensitive than that reported for PLB by HPLC-UV, which was $50 \mathrm{ng} / \mathrm{mL}[51]$.

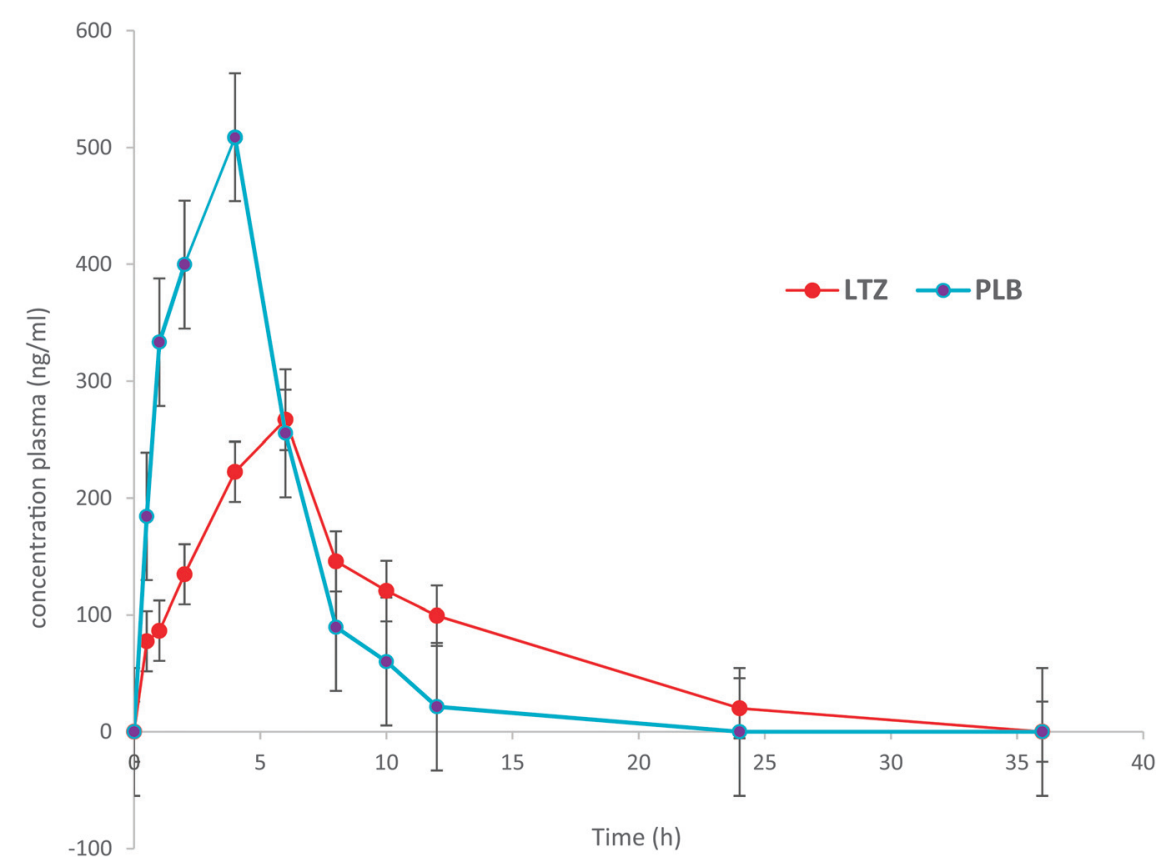

Figure 5. The concentration-time profile of the studied drugs in rats after a single intraperitoneal administration of combination of LTZ (2 mg/kg) and PLB $(25 \mathrm{mg} / \mathrm{kg})$ to rat 
Table 10. Mean pharmacokinetic parameters of LTZ and PLB in rat plasma after intraperitoneal administration of $2 \mathrm{mg} / \mathrm{kg}$ and $25 \mathrm{mg} / \mathrm{kg}$, respectively

\begin{tabular}{lccc}
\hline Parameter & Unit & LTZ & PLB \\
\hline $\mathrm{AUC}_{0-24}{ }^{a}$ & $\mathrm{ng} \mathrm{h} / \mathrm{mL}$ & $2784.61 \pm 521.36$ & $3393.52 \pm 243.27$ \\
$\mathrm{AUC}_{0-\infty}{ }^{b}$ & $\mathrm{ng} \mathrm{h} / \mathrm{mL}$ & $2784.61 \pm 521.36$ & $3393.52 \pm 243.27$ \\
$C_{\max }{ }^{d}$ & $\mathrm{ng} \mathrm{h} / \mathrm{mL}$ & $266.96 \pm 21.23$ & $508.75 \pm 61.56$ \\
$T_{\max }{ }^{2}$ & $\mathrm{~h}$ & $6.00 \pm 0.00$ & $4.00 \pm 0.00$ \\
$\mathrm{~K}_{\mathrm{e}}{ }^{f}$ & $\mathrm{ng} / \mathrm{mL}$ & $0.12 \pm 0.10$ & $0.53 \pm 0.07$ \\
$V_{\mathrm{d}}{ }^{g}$ & $\mathrm{~mL} / \mathrm{g}$ & $7.33 \pm 6.18$ & $15.63 \pm 6.56$ \\
$\mathrm{CL}^{g}$ & $\mathrm{~mL} / \mathrm{min} / \mathrm{kg}$ & $13.66 \pm 2.88$ & $77.73 \pm 32.71$ \\
$t_{1 / 2}{ }^{h}$ & $\mathrm{~h}$ & $7.11 \pm 6.42$ & $1.68 \pm 0.32$
\end{tabular}

${ }^{a}$ Area under the curve up to the last sampling time.

${ }^{b}$ Area under the curve extrapolated to infinity.

${ }^{c}$ The maximum plasma concentration.

${ }^{d}$ The time taken to reach maximum plasma concentration.

${ }^{e}$ Elimination rate constant.

${ }^{f}$ Volume of distribution

${ }^{g}$ Total clearance of drug from plasma after oral administration.

${ }^{h}$ Half-life.

\section{Conclusion}

The study has optimized a sensitive HPLC-PDA method that is able to determine LTZ and PLB in rat plasma at trace levels. The use of a HPLC technique with PDA detection resulted in sensitivity and selectivity for the determination of LTZ and PLB comparable to the use fluorescence or mass detection. Endogenous interference is removed in the developed method by simply performing deproteinization as a sample clean-up procedure, thereby achieving a high degree of selectivity. Because of the easy and short time sample preparation required, it has good precision and acceptable accuracy, wide linear range, and an especially low limit of detection. Therefore, this method appears to be adequate for the therapeutic and toxicological monitoring of LTZ combined with PLB in clinical practice and kinetics studies of these drugs.

\section{Conflict of Interest}

The authors declare that they have no conflict of interest.

Acknowledgment. The authors extend their appreciation to the Deanship of Scientific Research at King Saud University for funding the work through research group project no. RGPVPP-037.

\section{References}

1. Siegel, R.; Miller, K.; Jemal, A. Cancer J. Clin. 2017, 67, 7-30.

2. Lu, J. J. Hematol. Oncol. 2015, 8, 1-3.

3. Finn, R.; Crown, J.; Lang, I.; Boer, K.; Bondarenko, I.; Kulyk, S.; Ettl, J.; Patel, R.; Pinter, T.; Schmidt, M.; Shparyk, Y.; Thummala, A.; Voytko, N.; Fowst, C.; Huang, X.; Kim, S.; Randolph, S.; Slamon, D. Lancet Oncol. 2015, 16, 25-35.

4. Finn, R.; Martin, M.; Rugo, H.; Jones, S.; Im, S.; Gelmon, K.; Harbeck, N.; Lipatov, O.; Walshe, J.; Moulder, S.; Gauthier, E.; Lu, D.; Randolph, S.; Diéras, V.; Slamon, D. N. Eng. J. Med. 2016, 375, 1925-1936. 5. https://www.fda.gov/Drugs/InformationOnDrugs/ApprovedDrugs/ ucm549978.htm. Retrieved 15, Feb., 2019.

6. Asghar, U.; Witkiewicz, A.; Turner, N.; Knudsen, E. Nat. Rev. Drug Disc. 2015, 14, 130-146.

7. Shah, A.; Cristofanilli, M. Curr. Treat Options Oncol. 2017, 18, 6

8. Sablin, M.; Ricci, F.; Loirat, D.; Jobard, A.; Basse, C.; Romano, E.; Tourneau, C.; Dieras, V. Bull. Cancer 2017, 104, 114-122.

9. Xu, H.; Yu, S.; Liu, Q.; Yuan, X.; Mani, S.; Pestell, R.; Wu, K. J. Hematol. Oncol. 2017, 10, 97.

10. Ehab, M.; Elba, M. Breast Cancer 2016, 8, 83-91.

11. Chavana, B.; Tiwaria, S.; Shankarb, G.; Nimbalkarc, R.; Gargc, P.; Srinivasab, R.; Talluri, M. J. Pharm. Biomed. Anal. 2018, 157, 59-57.

12. Letrozole (Femara ${ }^{\circledR}$ tablets) https://www.accessdata.fda.gov/ drugsatfda_docs/label/2009/020726s018lbl.pdf. Retrieved 2, Feb., 2019

13. Novartis Pharmaceuticals Canada Inc, FEMARA ${ }^{\circledR}$ product monograph, Dorval, Quebec, 2008.

14. Aman, U.; Buzdar, M.; John, F.; Robertson, M.; Wolfgang Eiermann, M.; Jean-Marc Nabholtz, M. Cancer 2002, 95, 2006-16.

15. Acharjya, S.; Mallick, P.; Panda, P.; Kumar, K.; Annapurna, M. J. Adv. Pharm. Tech. Res. 2010, 1, 348-435.
16. Ganesh, M.; Kamalakannan, K.; Patil, R.; Upadhyay, S.; Srivatsava, A.; Sivakumar, T. Rasayan J Chem. 2008, 1, 155-158.

17. Mondal, N.; Pal, T.; Ghosal, S. Pharmazie 2007, 62, 597-598.

18. Shrivastava, A.; Chakraborty, A.; Rambhade, S.; Patil, U. Pharm. Sin. 2011, 2, 263-269.

19. Ganesh, M.; Rajasekar, K.; Bhagiyalakshmi, M.; Vinoba, M.; Saktimanigandan, K.; Jang, H. Trop. J. Pharm. Res. 2010, 9, 505-510.

20. Pallavi, S.; Vasanth, P.; Ramesh, T.; Malothu, R. Int. Res. J. Pharm. 2012, 3, 202-204.

21. Nataraj, K.; Kiran, K.; Ravinder, R.; Kesinath, R.; Vrushabendra, S. Res. J. Pharm. Biol. Chem. Sci. 2012, 3, 658-676.

22. Sekar, V.; Jayaseelan, S.; Subash, N.; Kumar, E.; Perumal, P.; Venkatesh, R.; Sekar, M. Int. J. Pharm. Res. Dev. 2009, 1, $1-7$.

23. Laha, T.; Patnaik, R.; Sen, S. Indian J. Pharm. Sci. 2008, 70, 401-403.

24. Mondal, N.; Pal, T.; Ghosal, S. Acta Pol. Pharm. 2009, 66, 11-17.

25. Pfister, C.; Duval, M.; Godbillon, J.; Gosset, G.; Gygax, D.; Marfil, F.; Sioufi, A.; Winkler, B. J. Pharm. Sci. 1994, 83, 520-524.

26. Ping, G.; Yuru. L.; Yuxia, W.; Sumei, J. Chin. J. Pharm. 2001, 7, $317-$ 318.

27. Acharjya, S.; Bhattamisra, S.; Muddana, B.; Bera, R.; Panda, B.; Mishra, G. Sci. Pharm. 2012, 80, 941-953.

28. Berzas, J.; Rodriguez, J.; Contento, A.; Cabello, M. J. Sep. Sci. 2003, 26, 908-914

29. Rodríguez-Flores, J.; Salcedo, A.; Llerena, M.; Fernández, L. J. Chromatogr. A 2008, 1185, 281-290.

30. Rodríguez-Flores, J.; Contento Salcedo, A.; Villaseñor Llerena, M.; Muñoz Fernández, L. Electrophoresis 2008, 29, 811-818.

31. Flores, J.; Salcedo, A.; Fernández, L. Anal. Chem. Insight. 2008, 3, 91101.

32. Rodríguez-Flores, J.; Contento-Salcedo, A.; Muñoz Fernández, L. Electrophoresis 2009, 30, 624-632.

33. Rodríguez, J.; Castañeda, G.; Muñoz, L. J. Chromatogr. B 2013, $913-$ 914, 12-18. 146

34. Moussa, B.; El-Bagary, R.; Osman, E.; Anal. Chem. Lett. 2013, 3, 139

35. Zarghi, A.; Foroutan, S.; Shafaati, A.; Khoddam, A. Chromatographia 2007, 66, 747-750.

36. Marfil, F.; Pineau, V.; Sioufi, A.; Godbillon, S, J. Chromatogr. B Biomed. Sci. Appl. 1996, 683, 251-258.

37. Joshi, C.; Vishnubhatla, S.; Chakkirala, S.; Manama, S. Asian J. Pharm. Clin. Res. 2011, 4, 107-112.

38. Mareck, U.; Sigmund, G.; Opfermann, G.; Geyer, H.; Thevis, M.; Schänzer, W.; Rapid. Commun. Mass. Spectrom. 2005, 19, 3689-3693.

39. Beer, B.; Schubert, B.; Oberguggenberger, A.; Meraner, V.; Hubalek,

M.; Oberacher, H. Anal. Bioanal. Chem. 2010, 398, 1791-1800.

40. Mazzarin, M.; Botrè, F. Rapid. Commun. Mass. Spectrom. 2006, 20 , 3465-3476

41. Kang, M.; Hwang, Y.; Lee, W.; Kim, D. Rapid. Commun. Mass. Spectrom. 2007, 21, 252-264.

42. Shao, R.; Yu, L.; Lou, H.; Ruan, Z.; Jiang, B.; Chen, J. J. Biomed. Chromatogr. 2016, 30, 632-637.

43. Platova, A.; Miroshnichenko, I.; Ptitsina, S.; Yurchenko, N. Pharm. Chem. J. 2014, 48, 292-297.

44. Precht, J.; Ganchev, B.; Heinkele, G.; Brauch, H.; Schwab, M.; Mürdter, T. Anal. Bioanal. Chem. 2012, 403, 301-308.

45. Rodriguez-Mozaz, S.; Lopez de Alda, M.; Barceló, D. J. Chromatogr. A 2007, 1152, 97-115.

46. Shi, X.; Fan, T.; Yao, J. J. Hebei Univ. Sci. Technol. 2017, 38, 375382.

47. Kallepalli, P.; Annapurna, M. Int. J. Green. Pharm. 2018, 12, S270.

48. Sreelakshmi, M.; Sasidhar, R.; Raviteja, B. Invent. Rapid. Pharm. Anal. Qual. Assur. 2019, 2, 1-7.

49. Wang, L.; Qiu, F.; Song, W.; Wang, Z. Chin, J. New Drug 2017, 26 , $2468-2471$.

50. Shanghai Centre; Guangzhou Univ. Chin. J. Pharm. 2018, 49, 205-211.

51. Nalanda, R.; Srinivasa, A.; Gowri, D. Int. J. Pharm. Sci. Res. 2018, 9 , 3883-3888.

52. Tamura, K.; Mukai, M.; Naito, Y.; Yonemori, K.; Kodaira, M.; Tanabe, Y: Yamamoto, N.; Osera, S.; Sasaki, M.; Mori, Y; Hashigaki, S.; Nagasawa, T.; Ko Umeyama, Y.; Yoshino, T. Cancer Sci. 2016, 107, 75.

53. Nguyen, L.; Zhong, W.; Painter, C.; Zhang, C.; Rahavendran, S.; Shen, Z. J. Pharm. Biomed. Anal. 2010, 53, 228-234.

54. Smith, D.; Tella, M.; Rahavendran, S.; Shen, Z. J. Chromatogr. B Anal. Technol. Biomed. Life Sci. 2011, 879, 2860-5.

55. Dange, Y.; Bhinge, S.; Salinkhe, V. J. Toxicol. Mech. method 2018, 28, $187-194$.

56. Polson, C.; Sarkar, P.; Incledon, B.; Raguvaran, V.; Grant, R. J. Chromatogr. B Anal. Technol. Biomed. Life Sci. 2003, 785, 263-275.

57. Miller, J. C., and Miller, J. N., Statistics for Analytical Chemistry, 2nd Ed., Ellis Horwood, Chichester, England, 2005.

58. Guidance for Industry Bioanalytical Method Validation, U.S. Department of Health and Human Services, Food and Drug Administration, 2001.

59. The guidelines for care and use of experimental animals by the Committee for Purpose of Control and Supervision on Experiments on Animals (CPCSEA), 2003.

60. Guide laboratory animals for the care and use of $8^{\text {th }} \mathrm{ed}$. committee for the update of the guide for the care and use of laboratory animals Institute for laboratory animal research Division on earth and life studies, The National Academy of Sciences, USA, 2011. 